Rosenstiel School of Marine and Atmospheric Science University of Miami 4600 Rickenbacker Causeway

Miami, Florida 33149

\title{
Progress Report.
}

to the

DEPARTMENT OF FNERGY

EY-76-S-05-3801

TITLE

ECOLOGY OF SUBTROPICAL, SHALLOW WATER ENVIRONMENTS:

CHEMISTRY OF COPPER AND CHLORINE INTRODUCED INTO

MARINE SYSTEMS DURING ENERGY PRODUCTION

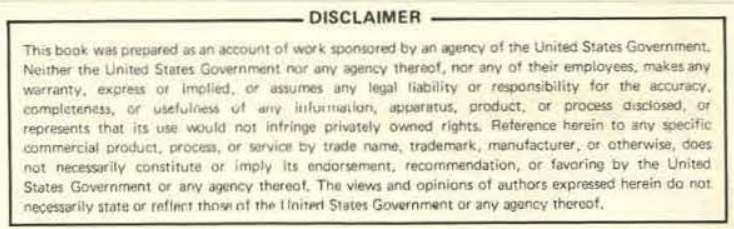

Principal Investigator

Jamfes H. Carpenter, Program Coordinator

For the Time Period

1 October, 1979 through 30 September, 1980

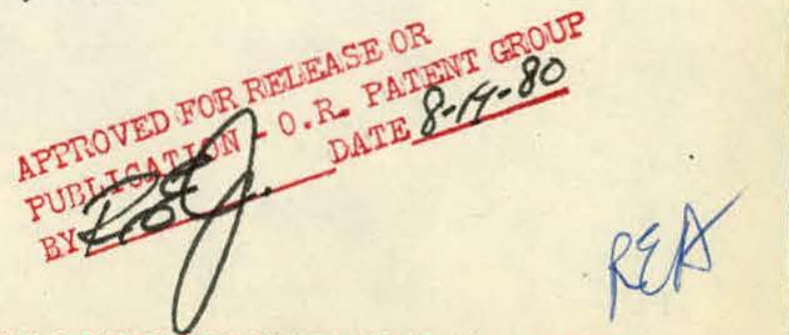




\section{DISCLAIMER}

This report was prepared as an account of work sponsored by an agency of the United States Government. Neither the United States Government nor any agency Thereof, nor any of their employees, makes any warranty, express or implied, or assumes any legal liability or responsibility for the accuracy, completeness, or usefulness of any information, apparatus, product, or process disclosed, or represents that its use would not infringe privately owned rights. Reference herein to any specific commercial product, process, or service by trade name, trademark, manufacturer, or otherwise does not necessarily constitute or imply its endorsement, recommendation, or favoring by the United States Government or any agency thereof. The views and opinions of authors expressed herein do not necessarily state or reflect those of the United States Government or any agency thereof. 


\section{DISCLAIMER}

Portions of this document may be illegible in electronic image products. Images are produced from the best available original document. 
DOE SUPPORTED PUBLICATIONS

Papers:

Carpenter, J. H., 1977. "Sunlight-induced bromate formation in chlorinated seawater", Sci., 195(4284): 1335-1337 (with D. L. Macalady and C. A. Moore).

Carpenter, J. H., 1977. "Errors in determination of residual oxidants in chlorinated șeawater", Env. Sci. and Tech., 11: 992-994 (with C. A. Moore and D. L. Macalady).

Carpenter, J. H., 1978. "Chemistry of halogens in seawater" In Water Chlorination: Environmental Impact and Health Effects, Vol. 1, edited by R. L. Jolley, P. 161-180. Ann Arbor, Mich., Ann Arbor Sci. Pub., Inc. (with D. L. Macalady).

Carpenter, J. H., 1978. "Reactions in chlorinated seawater", In Water ChIorination: Environmental Impact and Health Effects, Vol. 2, edited by R. L. Jolley, H. Gorchev, and D. H. Hamilton, p. 195-208. Ann Arbor, Mich., Ann Arbor Sci. Pub., Inc. (with C. A. Smith).

Abstracts :

Carpenter, J. H., 1977. "Problems in Measuring Residuals in Chlorinated Seawater", Chesapeake Sci., 18: 112.

Spencer, M. J., 1979. "The interactions between copper and organic matter in coastal seawater", Symposium on Dissertations on Chemical Oceanography, Oct. 8-12, 1979, Miami, Florida. 


\section{TABLE OF CONTENTS}

$\underline{\text { Page }}$

DOE SUPPORTED PUBLICATIONS . . . . . . . . . . . . . . 1

BACKGROUND . . . . . . . . . . . . . . . . . . 1

CURRENT WORK . . . . . . . . . . . . . . . . . 9

REFERENCES . . . . . . . . . . . . . . . . . 30

APPENDTX A: CURRENT PÜBLLLA'LLLNS . . . . . . . . . . . 33 
BACKGROUND

For many years, only total trace metal concentrations were measured in environmental samples. However, scientists are now aware that the speciation of these metals is important for predicting their biochemical and geochemical reactions. In seawater copper is present in both organic and inorganic forms. The principal inorganic form is thought to be $\mathrm{CuCO}_{3}$ with less than $1 \%$ of the total copper existing as the free $\mathrm{Cu}$ (II) ion (1). Very little is known about the organic copper species. This results from the lack of knowledge concerning the dissolved organic matter in seawater and from the limited information available concerning the biochemical cycle of copper in marine systems.

Copper is an essential element for life (2). Phytoplankton are sensitive to the activity of the free cupric ion $(3,4)$. There exists a lower limit for the $\mathrm{Cu}$ (II) ion activity beyond which nutritional deficiency occurs, in addition to an upper limit beyond which toxic symptons are produced. The chelating agent ethylene diaminetetraacetic acid is commonly added to culture media to chelate trace metal ions. Poor phytoplankton growth in upwelling areas is thought to arise due to insufficient concentrations of organic chelators (5). Phytoplankton growth was stimulated in this seawater after the addition of EDTA or a filtrate from a zooplankton homogenate but was not stimulated by the addition of trace metals, nutrients, vitamins, or amino acids. In some areas poor phytoplankton growth may instead be due to lack of utilizable trace metals with growth 
being stimulated by the addition of trace metals (6).

In any case, chelation by organics will result in an equivalent decrease in the amount of inorganic complexation and in a further decrease in the level of the free copper (II) ion. Ideally one would like to know the activity of the cupric.ion, however, there are presently no techniques by which this can be measured directly. The lack of information concerning the organic complexation equilibria prevents the calculation of this activity.

It is an extremely. difficult task to determine the organic speciation of a trace element. Few instrumental techniques can be used in the ppb concentration range and general concentration measures will disturb the speciation equilibria. The methods utilized for deterinining the concentration of organic copper attempt to capitalize on the differences in chemical behavior between the inorganic and the organic species. Common1y, such a determination yields a measurement of labile and non-1abile species. These species are characterized, respectively, by their reaction or lack of reaction in a given situation. Inorganic species are assumed to behave in a manner similar to the free copper (II) ion and are thereby included in the labile fraction. Organic species are then assumed not to be reactive without further treatment and thereby comprise the non-labile fraction.

Treatments such as acid digestion (7), UV oxidation (8), and chlorination (9) have been utilized for conversion of "organic" copper to a 
reactive form. Since the reaction mechanisms for these processes differ, there exists the possibility of differential release of copper. There is no generally accepted method for the determination of total copper. Recently Florence and Batley (10) have refined these procedures to determine seven types of metal species depending on combinations of anodic stripping voltammetry, chelex chromatography and ultraviniet light irradiation.

Another technique for the determination of "organic" copper, involves the separation and concentration of this fraction by liguid-liguid extraction with chloroform. The "organic" copper may not truly be extracted by the chloroform but may instead accumulate in the interfacial layer (11). Since the interfacial layer is commonly drawn off along with the chloroform, it will still be measured as "organic" copper.

These measures, though crude, do serve to establish limits for the concentration of organic copper in seawater. Slowey et al. (12) determined that $8-56 \%$ of total copper in the Gulf of Mexico was in an organic form by chloroform extraction. W11liams (13) found 0-28\% of total copper in an organic copper form based on concentration changes resulting from $U$ oxidation.

In order to gain information concerning the amount of organic chelators that are present in a water sample, the chelating capacity can be measured. In this procedure the water sample is titrated with copper (II) ions. After each addition of titrant, labile copper is measured by anodic 
stripping voltammetry (14) or free $\mathrm{Cu}$ (II) ion activity is measured with a copper ion selective electrode (15). The graph of measured copper versus titrant volume has two linear regions. In the first region with a smaller positive slope, much of the copper is reacting with organic chelators to form non-labile complexes. In the second region, the organic chelating capacity has been exceeded so that each additional increment of copper remalns in a labile form thus resulting in a greater stripping response per incremental addition. At the intersection point of the two lines, the amount of copper added equals the amount of organic chelating agent present (assuming a $1: 1$ complex). According to Chau, only those complexing agents forming complexes having stability constrants greater than $10^{13}$ will be measured by this titration. Surface active agents that adsorb onto the electrode surface will affect the electrode processes and may lead to significant error in the measurement of the complexing capacity by this technique $(16,17)$.

Estuarine areas (18) and lake waters (14) have been found to have similar complexing capacities of $0.1-0.6 \mu$ mole/l. This contrasts greatly with a heavily polluted river sample which possessed a chelating capacity of $25.4 \mathrm{~mole} / 1$ (15). The complexing capacity of the river water which flows into the Georgia estuary was spread evenly over the whole molecular weight range (18). In the estuary, as the salinity increased, the chelating capacity was derived to a greater extent by lower molecular weight compounds. 
Another method for the study of copper-organic interactions involves the use of model compounds. The choice of a suitable model compound is, however, fraught with problems. The majority of the organic matter in sea water is uncharacterized and is generally known as humic substances. This is a carryover of a name from soil organic work and does not necessarily indicate any structural similarity. The category humic substances is further subdivided into humic and fubic acids.

Humic acids are defined as that fraction of the organic matter that is soluble in basic but not in acidic solutions (19). Fulvic acids differ in that they are soluble in both acidic and basic solutions and generally possess lower molecular weights. These definitions, thus, key on general solubility characteristics of substances rather than on specific structural properties. These generic classes thus divulge very little structural or compositional information.

Fulvic acids from surface Sargasso sea water differed markedly in :

molecular weight distribution and in chromophore content from coastal water and soil fulvic acids (20). Thus, the use of reagent grade humic acid, which is of terrestrial origin, is not justified for sea water model expefiments. The use of humic compounds collected from the marine environment presents another problem, that due to chemical alteration of the substances during the concentration and separation procedures. Commonly the humic compounds are collected on XAD-2 resin from acidified sea water. The substances are eluted with strong ammonia solutions and 
the water removed by freeze drying or by using a rotary evaporator (21). These procedures may markedly change the chemical properties of the humic substances.

Despite these problems, several investigators have used humic substances as model compounds. By titrating a solution containing free $\mathrm{Cu}$ (II) ion with a reagent grade humic acid solution, O'Shea et al. (22) were able to demonstrate the formation of non-labile Cu-humate complexes. A dynamic equilibrium binding gel filtration procedure utilizing soil, peat, fresh water, marine and sediment humic compounds was used by Mantoura and Riley $(23,24)$ to demonstrate the formation of copper complexes. The fresh water humic compounds were found to contain approximately 3.5 times more complexing sites and result in the formation of stronger complexes than the soil humic compounds. Sea water humic substances formed complexes with stabilities equal to those from fresh waters. Equilibrium calculations using this data predict that as much as $80 \%$ of the copper is in an organic form. This prediction may be low since the speciation is calculated using overall complex stability constants. A small increase of the copper complex stability relative to the calcium and magnesium complex stabilities in a small percentage of the total chelating sites will increase the calculated concentration of "organic" copper. In many coastal areas there may be essentially no inorganic copper.

There is, however, no direct link between copper complexing substances 
and classical humic type compounds. Humic type compounds also form complexes with $\mathrm{Mg}$ and $\mathrm{Ca}$ as well so that few sites would remain available for copper chelation in sea water. Thus the stability constant determined from a model system may not give us all the information needed to assess the speciation of a metal. It is important that the stability constant of the copper complex be large, but of crucial importance is the selectivity for copper. Without this selectivity concentrations of free metals determine the extent to which each metal is complexed by the organic ligands. In this case copper would lose out to metals in higher abundance such as $\mathrm{Ca}, \mathrm{Mg}, \mathrm{Fe}$ and $\mathrm{Al}$. Only by invoking "some chelation specificity for copper, can organic chelation of copper be explained in the absence of biota.

Living organisms can greatly alter the speciation of an element. Since copper is an essential element like iron, copper sequestering agents may be secreted by phytoplankton resulting in the formation of a copper complex that can be assimilated by the phytoplankton. These compounds would thus be analogous to the iron sequestering siderophiles. Alternately excess siderophiles may act as copper chelating agents (25). Phytoplankton máy also act to detoxify ionic copper by exuding complexing agents. Excess intracellular copper may be converted to an organic water soluble form and excreted. These complexes may be kinetically stable in sea water and exist as dissolved copper species.

Thus, it is difficult to speculate as to the type of organics 
responsible for the chelation of copper. Humic acids seem a poor choice because of their general non-specific complexing capability. Peptides are a more likely source. Peptides and proteins possess structures that commonly produce high substrate specificities. Hydroxamic acids have been identified that are very specific iron chelators; perhaps there exist copper analogues. Due to the vast number of compounds synthesized by organisms there is a strong possibility that none of the above classes are at all important. If this is true, model experiments using these compounds are doomed to failure. More must be known concerning the actual chelators present in sea water before models can be useful. 


\section{Current Work}

The work in the present contract year has been directed towards three problem areas. The first area concerns the chromatography of copper organic complexes. This work is a continuation of study from previous contract years. The second concerns the use of chemical degradation experiments to determine the nature of the binding sites for copper. The third area concerns the investigation of various separation methods with the aim of separating the copper chelating substances from the remaining organic matter.

In the previous year a technique was established for studying natural seawater metal complexing reactions. The organic components were concentrated by ultrafiltration. The majority of the chelators were retained by a 500 molecular weight ultrafilter. Aliquots of the ultrafiltrand were then chromatographed on a sephadex G-25 column. The eluent was copper spiked gulfstream seawater. The sephadex column was equilibrated with the eluent so that there was no uptake of copper from the eluent as it passed through the column: The complexing organics are separated by molecular size and equilibrated with the backround level of copper in the eluent during their passsage through the column. By measuring the UV absorbance at $254 \mathrm{~nm}$ and total copper in the column fractions, the presence of organic components and copper chelators are detected. The presence of copper in. excess of the backround value except at the elution volume of free copper indicates the presence of copper chelators. 
Typical curves from Biscayne Bay ultrafiltrands are shown in figures 1 and 2. The smooth bell shaped curve in figure 1 represents the distribution of molecules from the sephadex separation and not just a broad distribution caused by peak broadening throughout the column. The copper distribution does not just mimic the UV distribution but possesses a maximum at a larger elution volume, interpretable as lower in molecular weight. Thus the average chelator appears to have a smaller size than the average UV absorbing molecule. Several samples from both nearshore and offshore locations in Biscayne Bay have been concentrated and chromatographed in this manner. The resulting chromatographs are similar to figures 1 and 2 . The ratio of peak UV absoxbance to peak of copper concentration varies by a factor of 2 . In all the striking result is that the distributions are so similar. One feature that does differ in these samples is the amount of material eluting at the void volume. Both a rise in UV and in total copper occurs there in chromatograms of certain samples. From this we can conclude that the organic matter is generally similar from one sample to another. However, the amount of high molecular weight material present in the organic matter appears to be very variable.

In order to study the lability of the complexes formed between copper and these natural organic ligands aliquots of the concentrates were chromatographed on sephadex G-25 columns that had not been equilibrated with copper. In this case, the columns had a considerable affinity for copper. The concentrate was prespiked so as to perform the copper complexes. Any 
Flgure 1. Ultraviolet absorbance $\lambda 254 \mathrm{~nm}$ : Sephadex G-25 Chromatography of Biscayne Bay water ultrafiltrand 2-14-79.

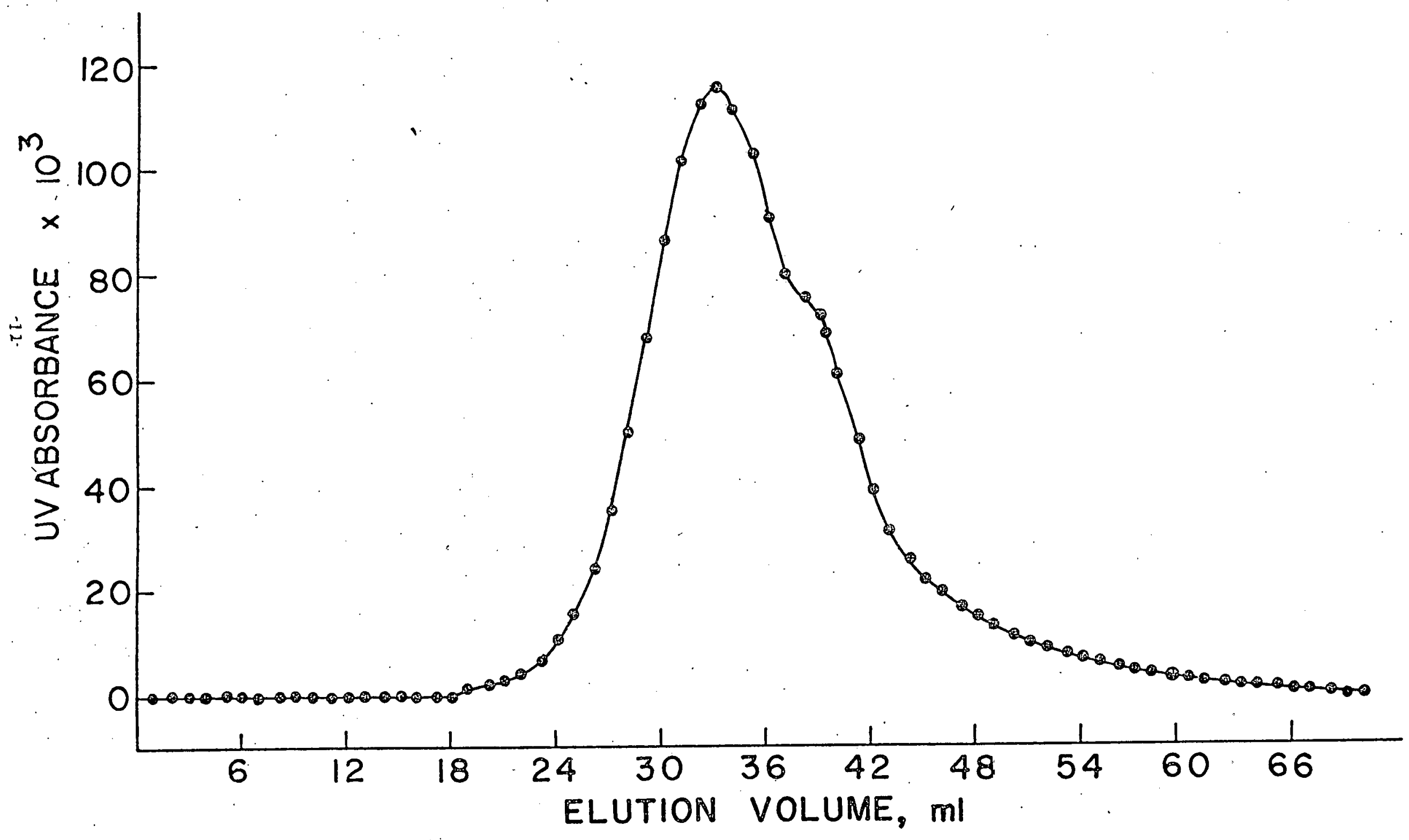


Figure 2. Copper content of fractions from sephadex G-25 chromatography of Biscayne Bay water ultrafiltrand 2-14-79.

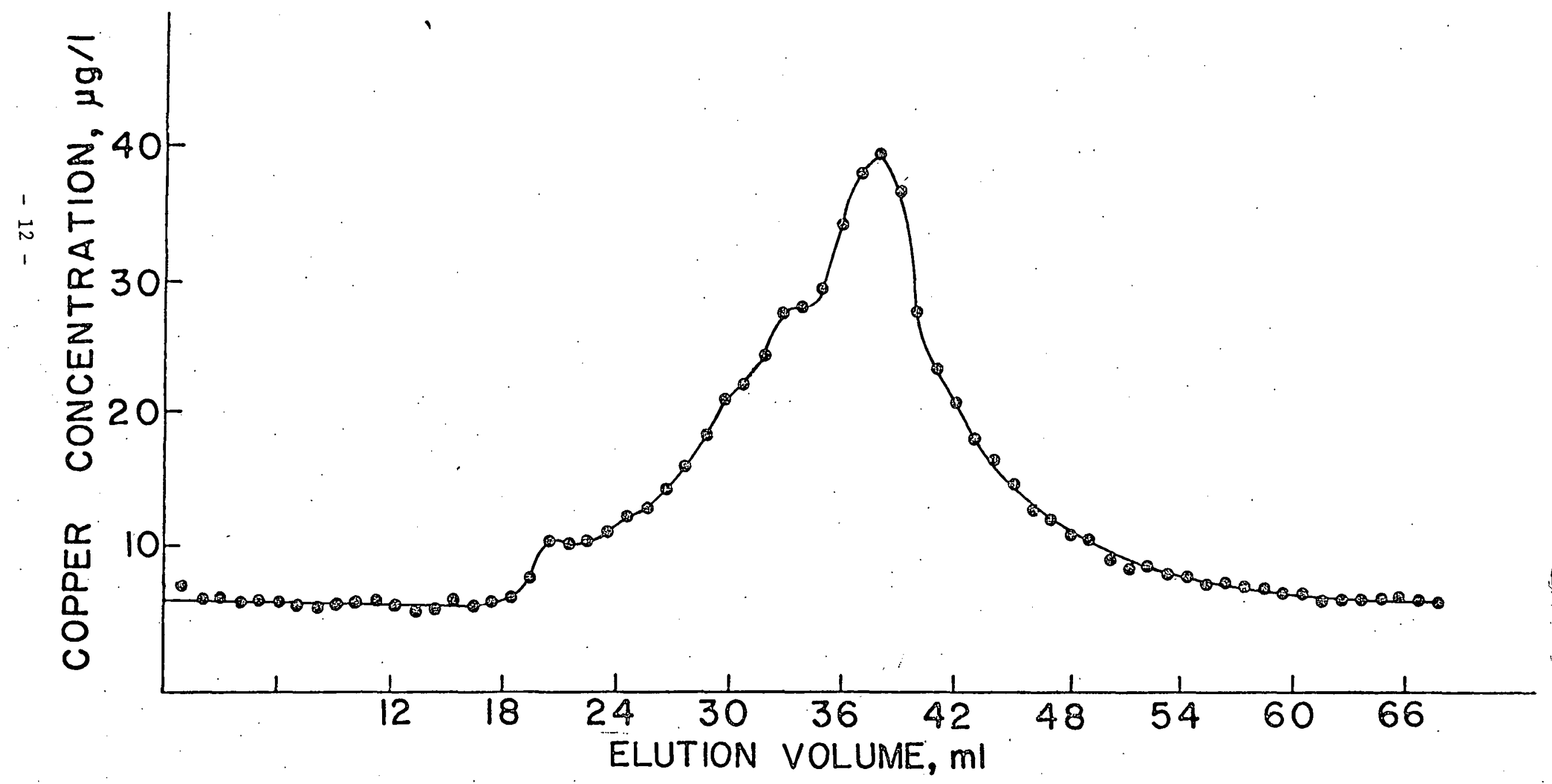


copper above the background level passing through the column indicates the presence of complexes that are kinetically stable during the time scale of the column transit of about $1.5 \mathrm{hrs}$. Any complex dissociating during transit would lose its copper to the column packing. The result was that there was a $41 \%$ recovery of complexed copper. The pattern of complexed copper was similar to the equilibrated results except that there was no large spike in the $38 \mathrm{ml}$ region. Thus both non-labile and labile organic complexes of copper must be considered as integral components of the species of copper present in natural waters.

By switching to distilled water as the eluent information is gained concerning the large number of general metal chelation sites. In this case the activity of free copper ions with which the chelating components equilibrate with is up to 400 times greater at the same total copper than with seawater. This arises because in distilled water there are much lower concentrations of inorganic complex forming ligands and because in distilled water the activity coefficient for free copper ions is nearly 1. In addition to this there is a large decrease in the concentrations of the competing ions $\mathrm{Mg}$ and $\mathrm{Ca}$.

The amount of chelators determined in this manner from the chromatographic run is about $100 \times$ greater than if seawater was used as the eluent. This may be in fact equal to the total number of available metal sites. The number of sites when calculated back to the original seawater sample amounts to 1-2 umoles per milligram organic carbon. This compares with a value 
of 11 umoles per milligram organic carbon ${ }^{26}$ of weak acid sites as determined by acid-base titration. Since one would expect copper complexes to adopt a coordination number of 4 when possible the two studies agree quite well. An important point is that the number of sites examined in our seawater studies is only $1 \%$ of this total. This small portion is quickly lost when faced by examination of the whole. This fact quickly points up the importanse of using seawater as the eluent in such studies. Another result is that in the distilled water run the copper peak is coincident with the UV absorption peak. The chelators of lower molecular weight seen in the seawater runs have been overshadowed by the general metal chelation sites present in the bulk of the organic matter.

So far the assumption has been made that the sephadex G-25 column packing separales the organic components purely by molecular size. There may, however, be chemical interactions between a component and the gel that produce separation of the organics in addition to separation processes that act based on molecular size alone. These chemical effects serve to retard the elution of the interacting component. The net result is that the component appears to be smaller than it actually is.

If gel permeation chromatography media separates purely by size then two different packings with similar pore size and resolution characteristics will yield similar chromatographs. The sephadex G-25 packing was compared to biogel $\mathrm{P}-2$. The results are seen in figures $3-6$. The UV results for biogel P-2 is similar to that for sephadex G-25. The peak obtained with. the biogel P-2 packing occurs at a volume closer to the void volume since the exclusion characteristics of the packings to differ. The exclusion limit 
Figure 3. Ultraviolet absorbance $\lambda 254 \cdot \mathrm{nm}$ : Sephadex $G-25$ chromatography of Biscayne Bay water ultrafiltrand $1-10-80$.

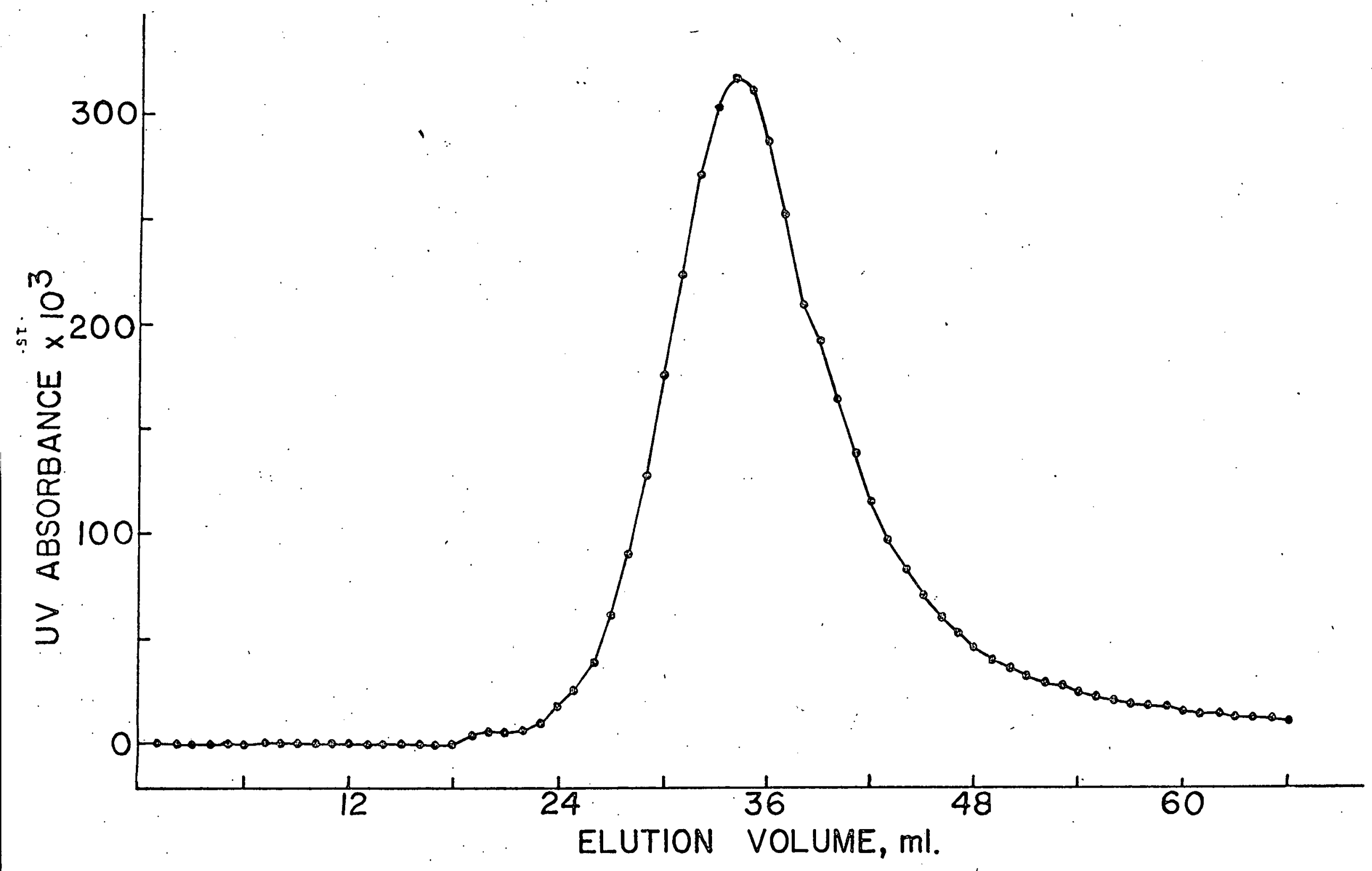


Flgure 4. U1traviolet absorbance $\lambda 254 \mathrm{~nm}$ : biogel P-2 chromatography of Biscayne Bay water ultrafiltrand 1-10-80.

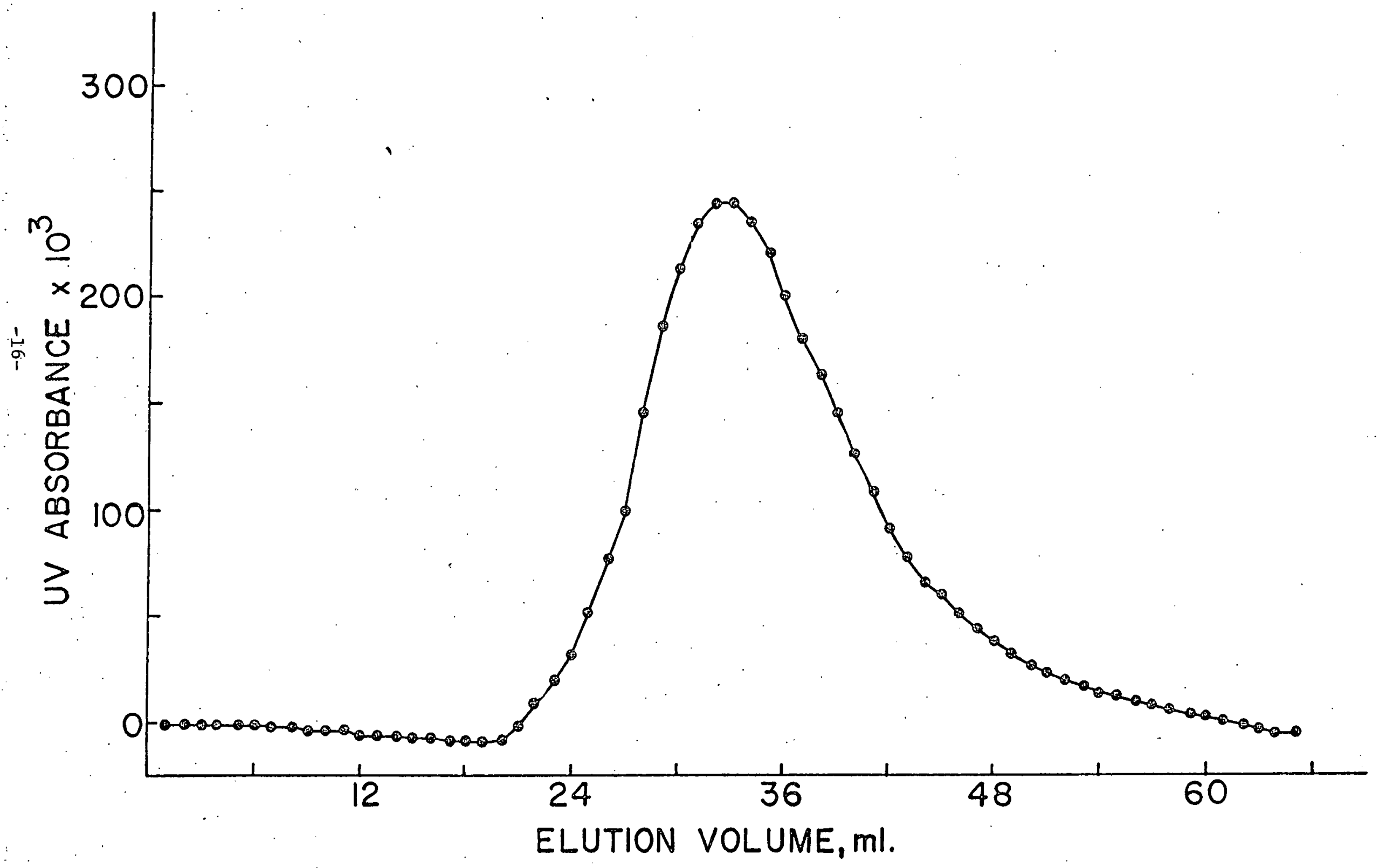


Figure 5. Copper content of fractions from sephadex. G-25 chromatography of Biscayne Bay water ultrafiltrand 1-10-80.

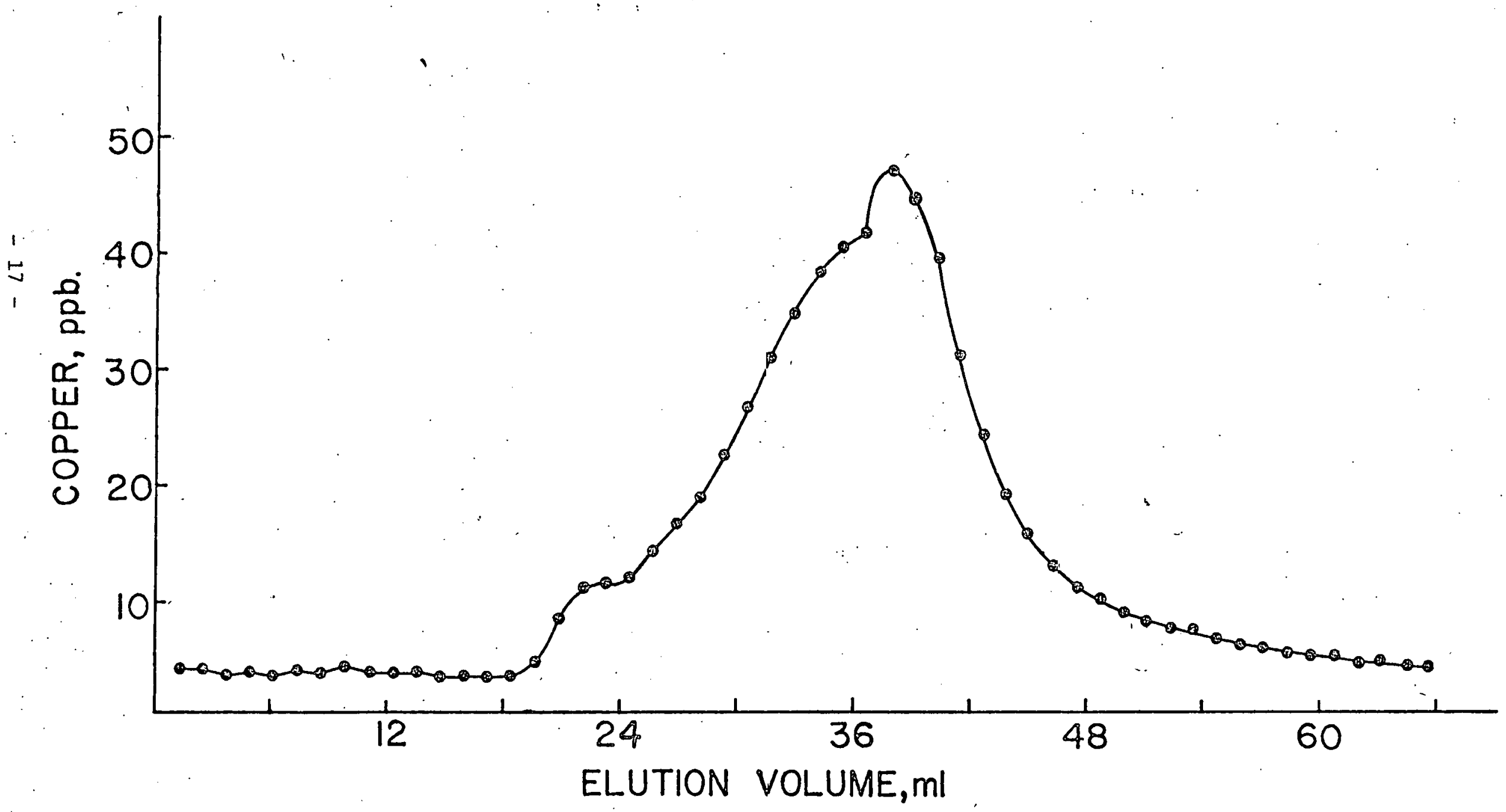


Figure 6. Copper contents of fractions from bioge1 P-2 chromatography of Biscayre Bay water ultrafiltrand 1-10-80.

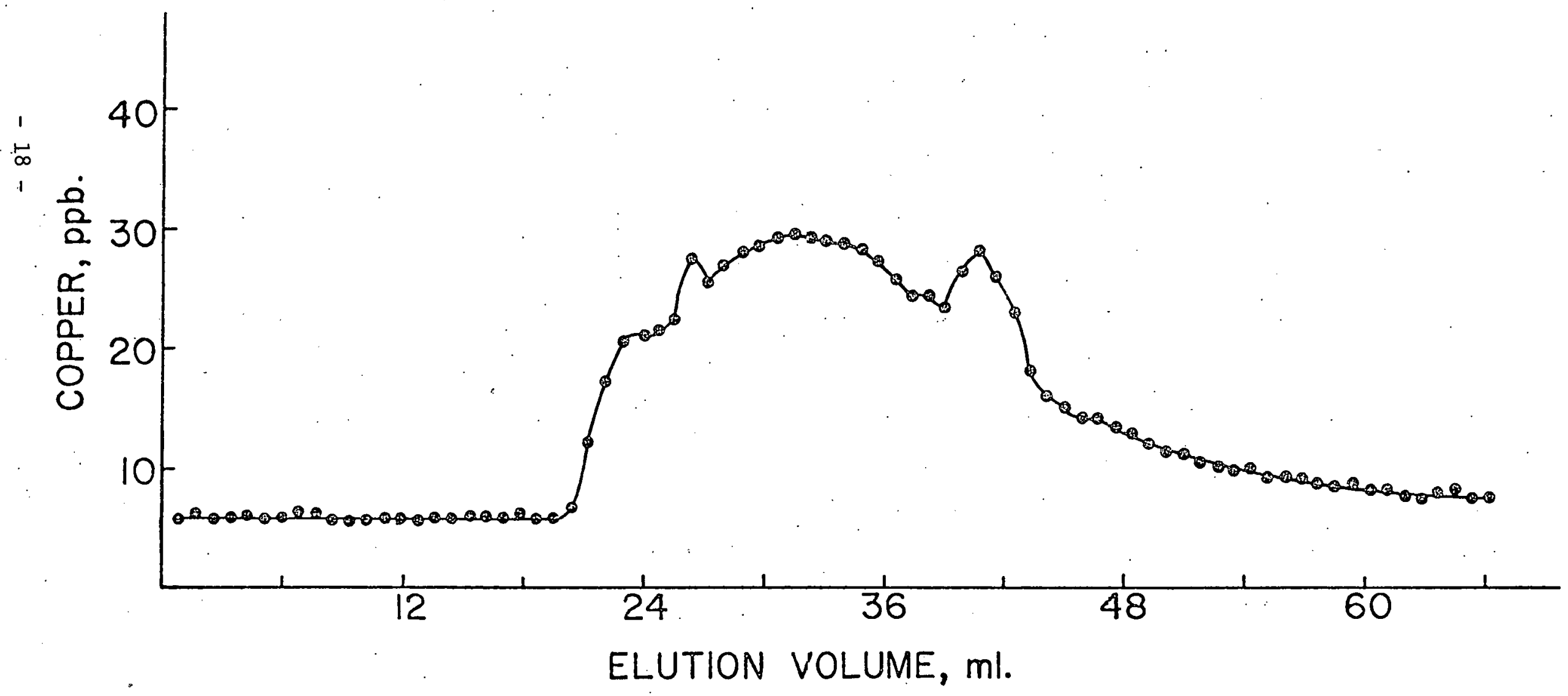


for biogel P-2 is 1800 daltons whereas that for sephadex G-25 is 5000 daltons. The total integrated UV absorbance from the biogel P-2 run indicates a loss of about $20 \%$ as compared to elution on sephadex G-25. In agreement with the UV runs there are $20 \%$ fewer copper chelators in the biogel P-2 profile. The copper profiles for the two columns are widely different. Thus, the apparent molecular weight distributions for the majority of the organic components are consistant and probably represent a true molecular weight distribution. The copper complexing components important in a seawater matrix are a completely different story. With biogel P-2 the copper peak is coincident with the UV peak. There is in addition a large rise in copper just after the void volume. This would indicate that a large portion of the chelating substances are of higher molecular weight than the average organic component. The biogel profile probably represents the profile closer to the real distribution. Column effects normally retard the elution of a component, not accelerate it. This does not totally invalidate the sephadex profiles. These profile are probably not purely based on molecular size but on some combination of molecular size and sephadex affinity. Such a distribution will still be consistant from run to run as long as the same packing material is used. Thus, the average copper chelator seens to interact more strongly with the sephadex matrix than the average UV absorbing component.

In an effort to determine the nature of the copper complexing sites, degradation experiments were carried out. The concentrate was subjected to acid hydrolysis. The sample was diluted 1:1 with concentrated $\mathrm{HCl}$, and the 
vessel was evacuated and capped. The reaction vessel was kept at $110^{\circ}$ for 24 hours. Such a hydrolysis should result in the rupture of all peptide bonds. Such a hydrolysis also results in complete destruction of tryptophan. Typical results can be seen in figures $7-10$. The hydrolysate was neutralized with $\mathrm{NaOH}$ as soon as it cooled down. The profiles for hydrolysate have been corrected for dilution and for the reagent blank. The large UV peak occurring at $47 \mathrm{ml}$ in the hydrolysate is a variable component from the reagents which has not been accounted for in the reagent blank. The most obvious results are the loss of UV signal and copper content in the region of the void volume and the general lower amount of copper in the hydrolysate profiles. The UV absorbance from the hydrolysate has decreased only $33 \%$ as compared to the original concentrate. Thus, the backbone of the organic matter is definitely not proteinaceous. Since this decrease occurs over the entire molecular weight range, the proteinaceous components may have existed as side chains on a wide variety of molecules.

The hydrolysate has lost about $52 \%$ of its complexing capability. The percentage decrease is lowest at the copper peak maximum and greatest at lower elution volumés. Thus, it would appear that the higher molecular weight complexes are more proteinaceous than those of lower molecular weight and that those components with molecular weights approaching or exceeding the exclusion molecular weight are completely proteinaceous. This latter conclusion agrees with the results of Tuschall and Brezonik 27 
Figure 7. UV absorbance $\lambda 254 \mathrm{~nm}$ : Sephadex G-25 chromatography of RSMAS dock water ultrafiltrand 9-30-79.

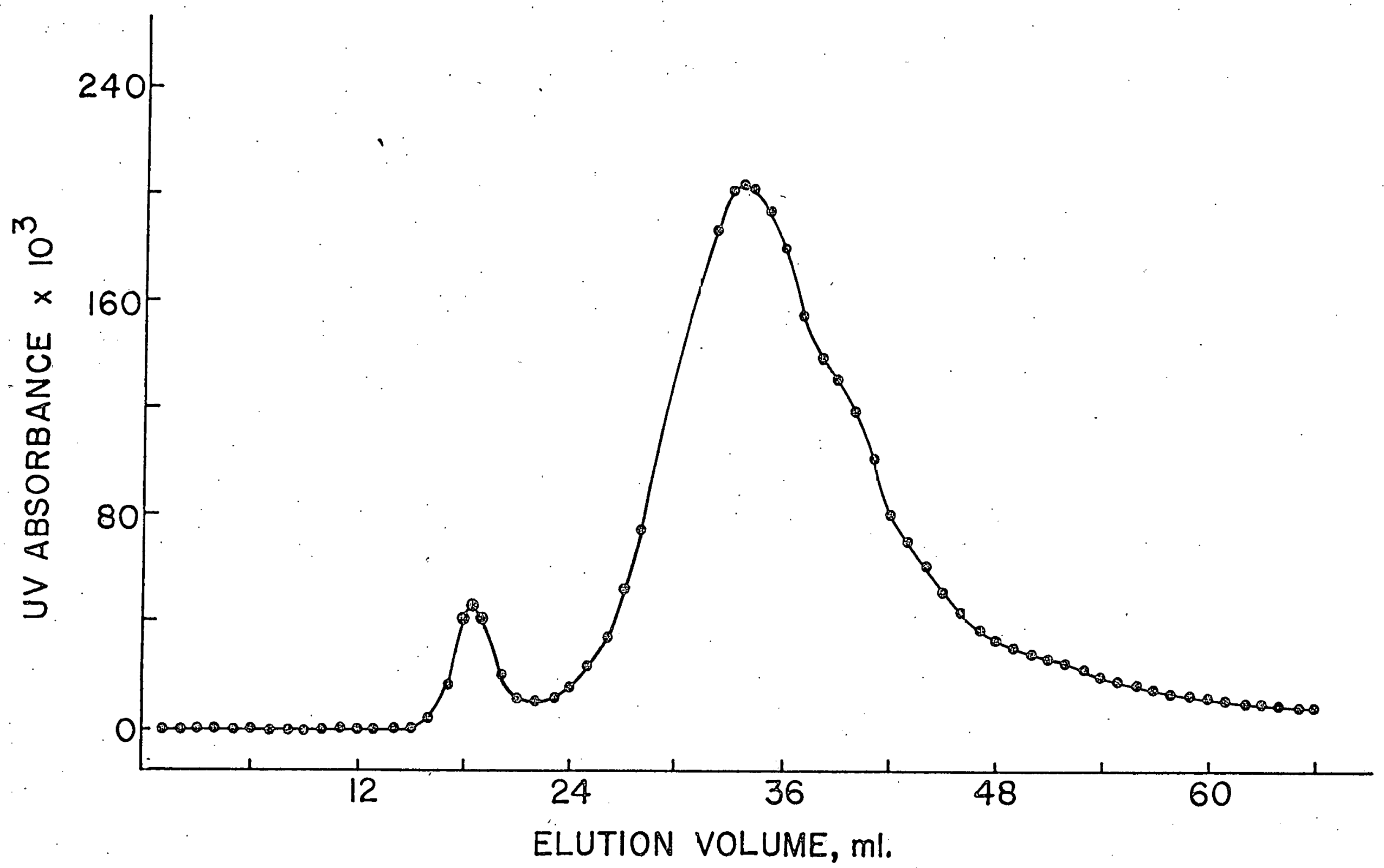




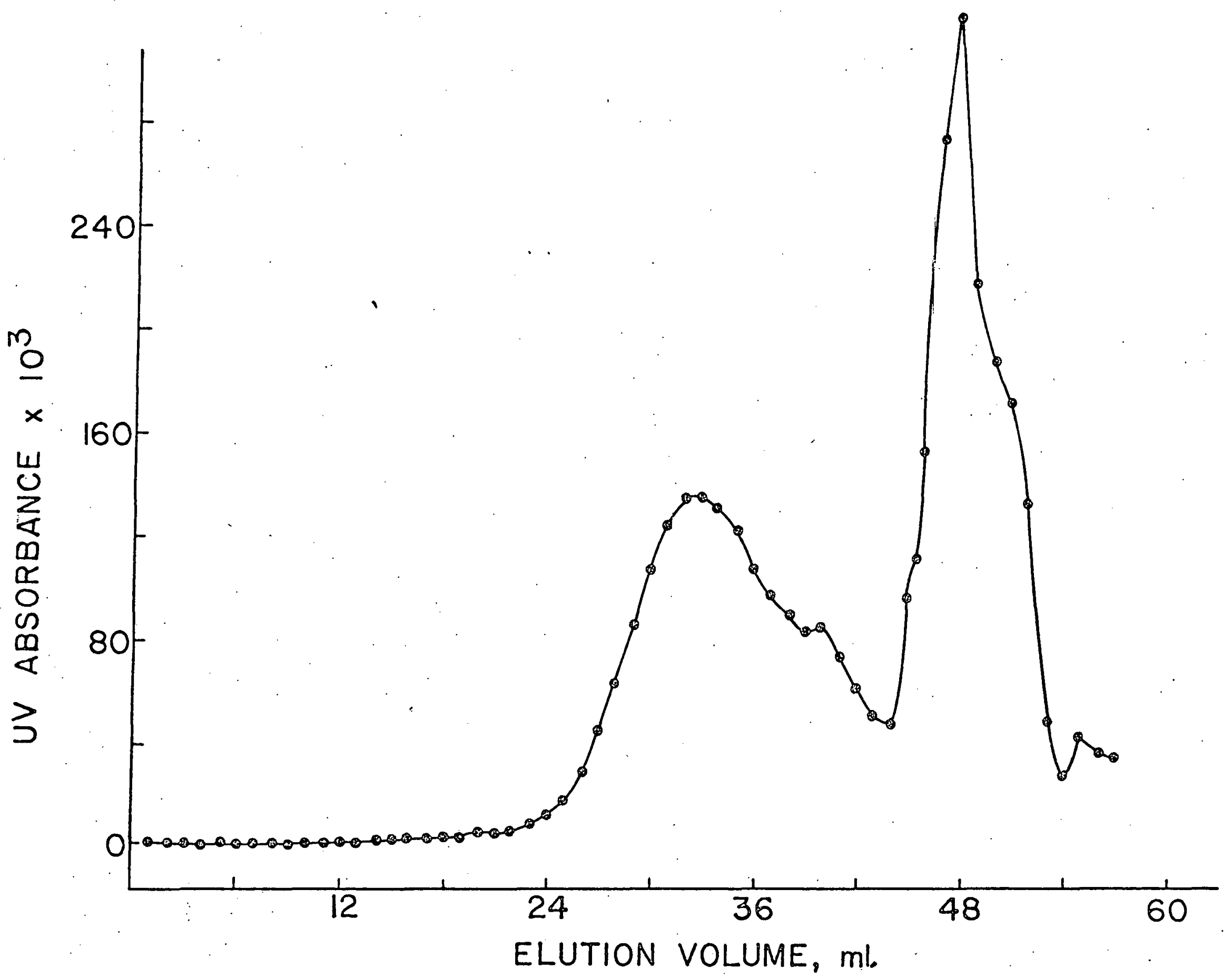

Figure 8. UV absorbance $\lambda 254 \mathrm{~nm}$ corrected for dilution and reagent blank: Sephadex G-25 chromatography of acid hydrolysate of RSMAS dock water ultrafiltrand 9-30-79. 
Figure 9. Copper content of fractions from sephadex G-25 chromatography of RSMAS dock water ultrafiltrand 9-30-79.

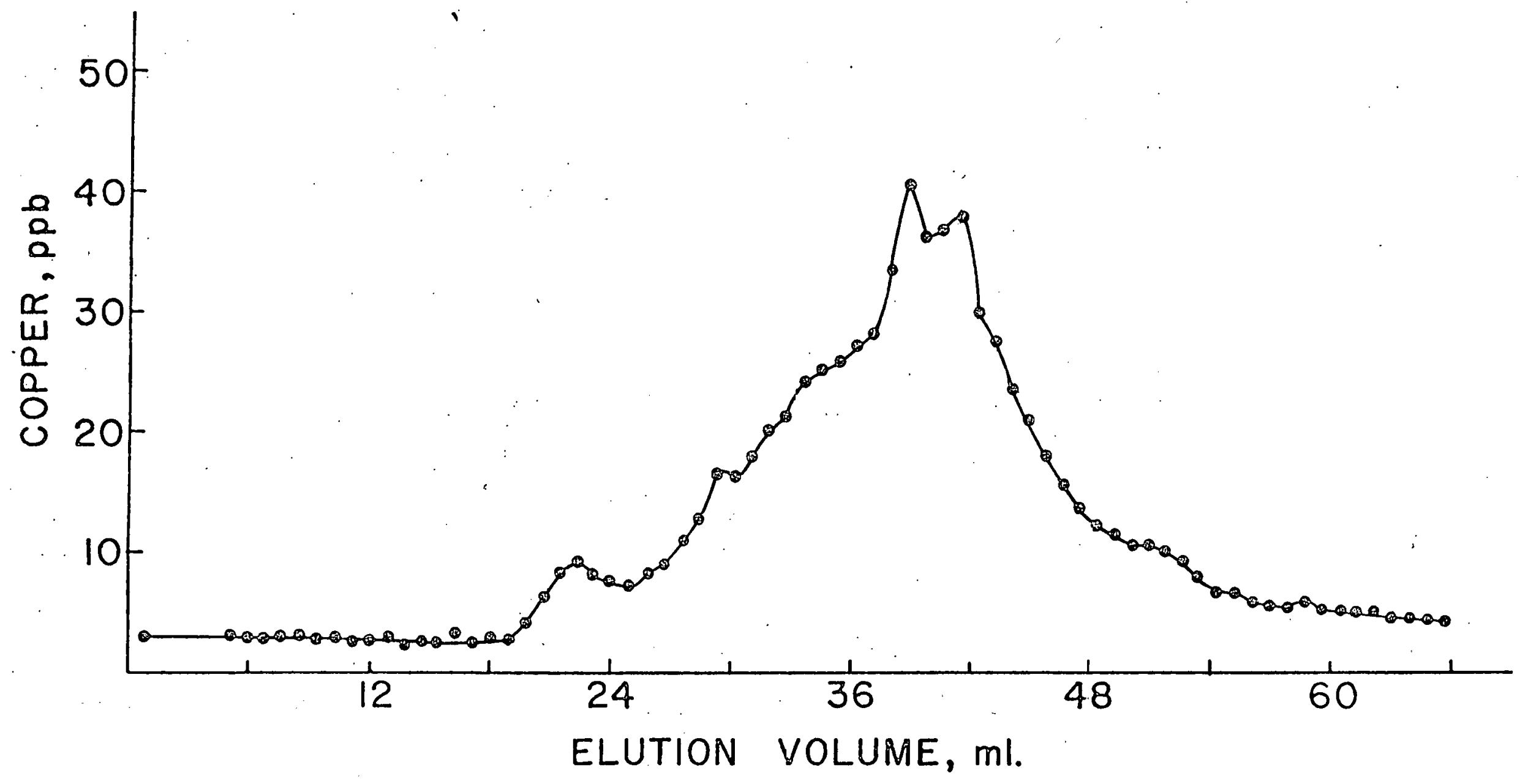


Figure 10. Copper content corrected for dilution and reagent blank of fractions from sephadex G-25 chromatography of acid hydrolysate of RSMAS dock water ultrafiltrand 9-30-79.

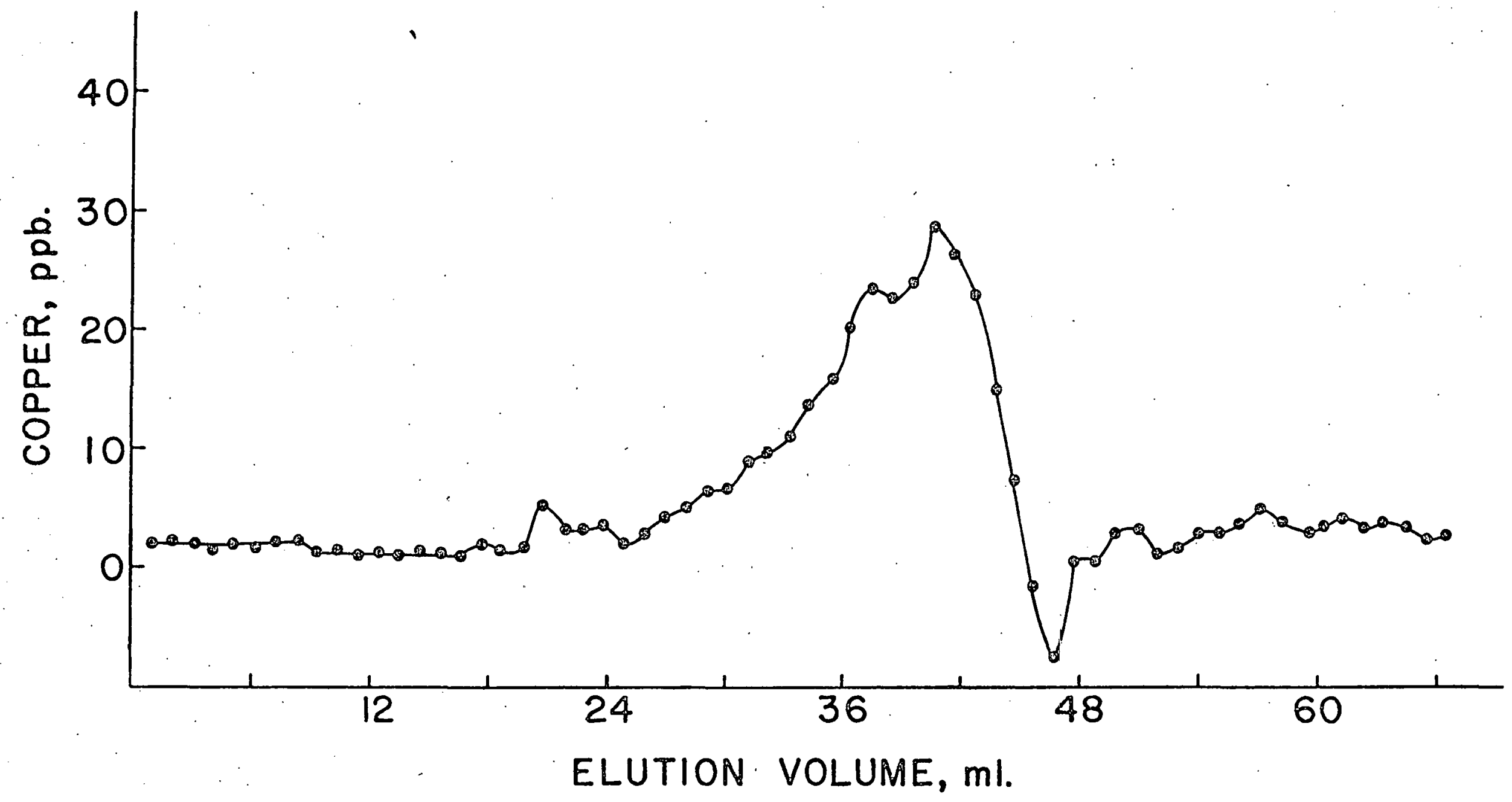


which indicate that the high molecular weight organics are predominately proteinaceous.

From this and the preceeding studies it has been shown that the copper chelating substances are heterogeneous in all characteristics so far determined. This greatly increases the difficulty involved in their eluci- . dation. Once again, the natural world has been shown to be a complex situation free of quick and easy solutions to problems.

In order to progress further with this study, it will be necessary to separate out the copper chelators from the remainder of the organic matter with its general metal sites. Two techniques have been studied for this separation capability. In the previous year a C-18 bonded phase mini-1iquid chromatography trap (Waters SEP-PAK C-18) was studied for organic concentration capability at natural $\mathrm{pH}$. This medium was found to retain only a small percentage of the organic matter. This year the organic retention experiment was repeated except that the $\mathrm{pH}$ of the sample was decreased to 2 . At this $\mathrm{pH}$ about $44 \%$ of the organic eluted from the trap passed right through the trap. Another $44 \%$ were released when the $\mathrm{pH}$ of the eluent seawater was changed to its natural $\mathrm{pH}$. A second switch of eluent to $10 \% \mathrm{MeOH}$ in seawater released $13 \%$ more of the organic matter. The fraction that marches right through the trap accounts for $70 \%$ of the chelators present in the concentrate aliquot. The ratio of copper content to UV absorbance in this fraction is increased by a factor of 3 over the original sample. The distribution of UV and copper content from a sephadex G-25 run of this fraction is similar to the original sample. 
The UV shows a more distinct shoulder in the $36-38 \mathrm{ml}$ region. The copper profile also shows an increase in this region. Since the desired fraction is not being held on the column this method is not suitable for the concentration of the chelating organics. Even though the separation is far away from the desired 1:100 separation it comes a long way with a relatively crude technique and will be useful as a quick enrichment technique.

The second method involves the use of a copper chelex column similar to those used for concentration of amino acids from seawater. The idea is that the chelators will be retained as copper chelate by the column. The remaining components will pass unhindered right through the column. The chelators would then be released like the amino acids by $2 \mathrm{M} \mathrm{NH}_{4} \mathrm{OH}$. This works for amino acids so by analogy it should work for our chelators. There are two important considerations to be made concerning this process. The first is that the column may retain many more components than those sought since the high content of copper in the column may result in the retention of components whose copper complex seawater association constants are much lower than those that we desire to study. The second consideration is that the strong chelators may not be satisfied with the 1-2 coordination sites available at the résin attached copper. This may result in the removal of copper from its resin site. The complex would then pass right through the remainder of the coluinn.

The first column chosen was $5 \times 1 \mathrm{~cm}$ and included a plug of chelex in the $\mathrm{Na}^{+}$form at the end to remove copper eluted by the ammonia. Without this. 
there was a considerable backround UV absorbance from the copper ammonia complex. The ultrafiltrand sample passed right through this column. It would appear that our second consideration is valid in this case.

In order to increase the ability of the column to retain its copper a packing that was only $50 \%$ saturated was obtained by mixing equal portions of saturated $\mathrm{Cu}$-chelex with $\mathrm{Na}^{+}$-chelex. The column size was increased to $2.2 \times 30 \mathrm{~cm}$. The end of the column was again filled with $\mathrm{Na}^{+}$-chelex. The elution of a $5 \mathrm{ml}$ aliquot of a concentrate is shown in figure 11 . The first peak at $75 \mathrm{ml}$ represents components passing right through the column. The second peak at $192 \mathrm{ml}$ represents organics retained by the column and eluted with $0.008 \mathrm{~N} \mathrm{NH}_{4} \mathrm{OH}$. Overall there was a $75 \%$ recovery in UV absorbance from the original sample. The integrated IV ahsorbance contained in the two peaks correspond to a $1: 1$ ratio. The dilution of the components eluting as the first peak made this fraction unsuitable for further study. The second fraction corresponds to $80 \%$ of the chelators present in the original aliquot. The $\mathrm{Cu} / \mathrm{UV}$ ratio has been enriched by a factor of 1.7 .

This technique does not separate out our chelator fraction as well as the $\mathrm{C}-18$ trap. In this case, however, the chelator fraction is retained by the column. This technique thus may be better suited for use as a general concentration procedure. The ultrafiltration technique used so far is fine with Biscayne Bay samples when a concentration factor of 100 is needed. The resin column may allow us to study other waters having lower concentrations of chelating organics.

So far the door to the elucidation of the chemical nature of the copper 
Figure 11. UV absorbance $\lambda 254 \mathrm{~nm}$ : copper-chelex chromatography of Biscayne Bay water ultraf 11 trand $1-10-80$.

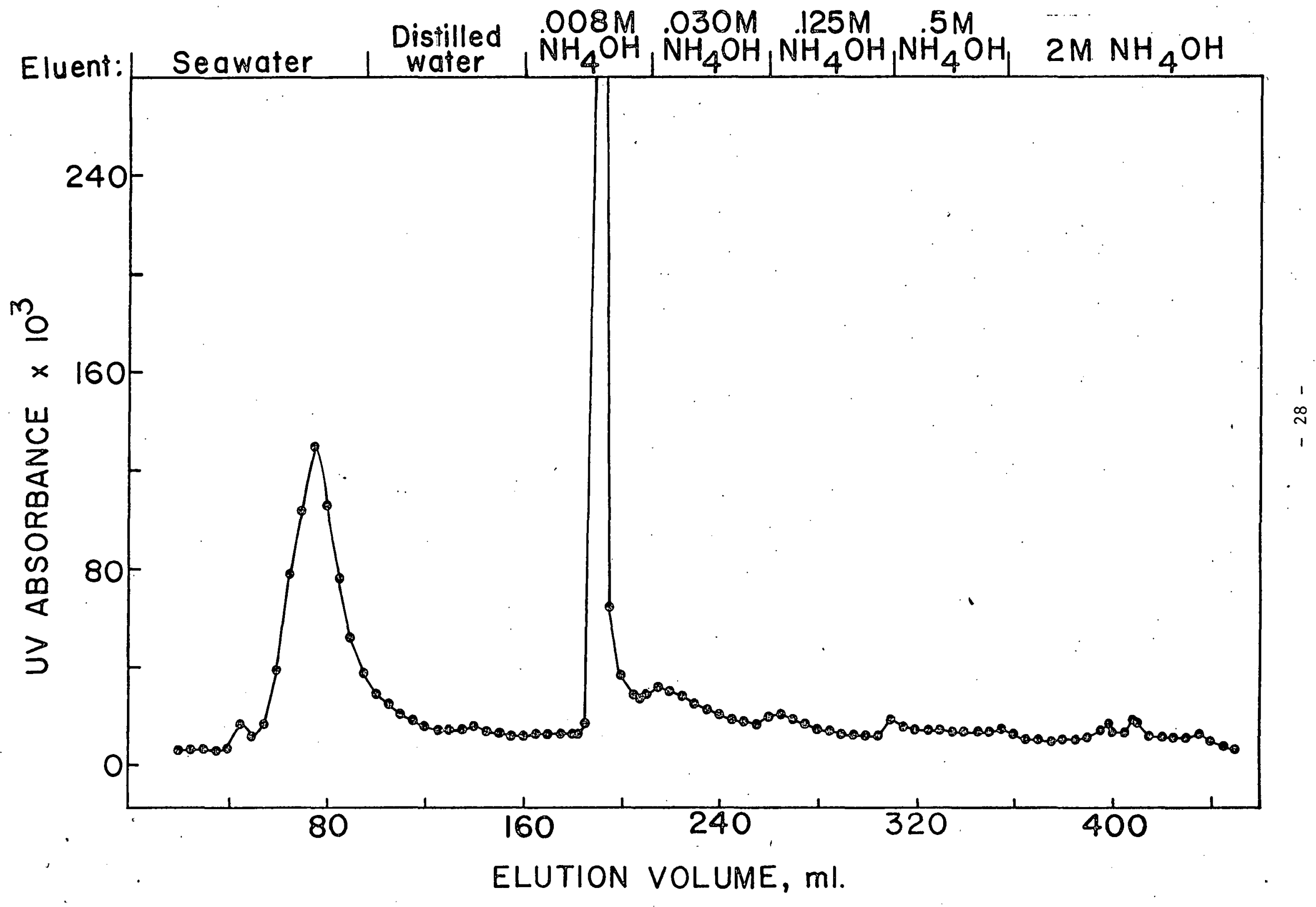


complexing organics has been pushed open a bit. The complex nature of these components results in small hard won accomplishments. These compounds have been shown to possess a wide range of molecular weights. Some of these complexes are labile and others are non-labile in a 1-2 hour time scale. Approximately half of the copper chelation sites are predominantely proteinaceous. Further study is needed to determine the complete nature of these chelating organics. 


\section{REFERENCES}

1. Dryssen, D. and Wedborg, M., 1974. "Equilibrium calculations of the speciation of elements in seawater." in The Sea, Vol. 5, E. Goldberg, ed., John Wiley \& Sons, New York, pp 181-195.

2. Frieden, E., 1974. "The evolution of metals as essential elements [with special reference to iron and copper]." Adv. Exp. Med. Bio. 48: $1-31$.

3. Sunda, W. dlld Gulllard, R., 1976. "l'he relationship between cupric ion activity and the toxicity of copper to phytoplankton." J. Mar. Res. 34: $511-529$.

4. Manahan, S.E. and Smith, M.E., 1973. "Copper micronutrient requirement for algae." Anal. Chem. 7: 829-833.

5. Barber, R.T. and Ryther, J.H., 1969. "Organic chelators: Factors affecting primary production in the Cromwell current upwelling." J. Exp. Mar. Biol. Ecol. 3: 191-199.

6. Ortner, P.,.1980. Personal communication.

7. Chau, Y.K. and Lum-Shue-Chan, K., 1974. "Determination of labile and strongly bound metals in lake water," Water Res. 8: 383-388.

8. Foster, P. and Morris, A.W., 1971. "The seasonal variation of dissolved ionic and organically associated copper in the Menai Straits." Deep Sea Res. 18: $-231-236$.

9. Carpenter, J.H. and Smith, C.A., 1978. "Reactions in chlorinated seawater." in Water Chlorination: Environmental Impact and Health Effects, Vol. 2, Ann Arbor Science Publishing, Inc., Ann Arbor, pp 195-207.

10. Florence, T.M. and Batley, G.E., 1976. "Determination of the chemical forms of dissolved cadmium, lead and copper in seawater." Mar. Chem. 4: $347-363$.

11. Piotrowicz, S., 1979. Personal communication.

12. Slowey, J.F., Jeffrey, L.M. and Hood, D.W., 1967. "Ev1dence for organic complexed copper in sea water." Nature 214: 377-378.

13. Williams, P.M., 1969. "The association of copper with dissolved organic complexed copper in sea water." Limnol. Oceanogr. 14: 156-158. 
14. Chau, Y.K., Gachter, R. and Lum-Shue-Chan, K., 1974. "Determination of the apparent complexing capacity of lake waters." J. Fish. Res. Board. Canada 31: 1515-1519.

15. Ramamoorthy, S. and Kushner, D.J., 1975. "Heavy metal binding sites in river water." Nature 256: 399-401.

16. Brezonik, P.L., Brauner, P.A. and S.tumm, W., 1976. "Trace metal analysis by anodic stripping voltammetry. Effect of sorption by natural and model organic compounds." Water Res. 10: 605-612.

17. Batley, G.E. and Florence, 'L.M., 1976. "The effect of dissolved organics on the stripping voltammetry of seawater." J. Electroanal. Chem. Interfacial Electrochem. 72: 121-126.

18. Smith, R.G., 1976. "Evaluation of combined applictions of ultrafiltration and complexation capacity techniques to natural waters." Anal. Chem. 48: 74-76.

19. McCarthy, P.L. and Mark, H.B., 1975. "Prespectives in humic acid research. I. The nature and functions of humic substances." unpublished manuscript.

20. Stuermer, D.H. and Harvey,.G.R., 1974. "Humic substances from seawater." Nature 250: 480-481.

21. Mantoura, R.F.C. and Riley, J.P., 1975. "The analytical concentration of humic substances from natural waters." Anal. Chim. Acta 76: 97-106.

22. O'Shea, T.A. and Mancy, K.H., 1976. "Characterization of trace metalorganic interactions by anodic stripping voltammetry." Anal. Chem. 48: 1603-1607.

23. Mantoura, R.F.C. and Riley, J.P., 1975. "Use of gel filtration in the study of metal binding by humic acids and related compounds." Anal. Chim. Acta 78: 193-200.

24. Mantoura, R.F.C., Dickson, A. and Riley, J.P., 1978. "The complexation of metals with humic materials in natural waters." Estuarine and Coastal Mar. Sci. 6: 387-408.

25. McKnight, D.M. and More1, F.M.M., 1980. "Copper complexation by siderophiles from filamentous blue-green algae." Limnol. Oceanogr. 25: 62-71. 
26. Huizenga, D.L. and Kester, D.R., 1979. "Protonation equilibria of marine dissolved organic matter." Limnol. Oceanogr. 24: 145-150.

27. Tuschall, Jr., J.R. and Brezonik, P.L., 1980. "Characterization of organic nitrogen in natural vaters: Its molecular size, protein content, and interactions with heavy metals." Limnol. Oceanogr. 25: 495-504. 
Appendix A

THE INTERACTIONS BETWEEN COPPER AND ORGANIC MATTER IN COASTAL SEAWATER

Mary Jo Spencer

University of Miami

The objective of this research is to further the understanding of the interactions between copper ions and the organic components of coastal waters. Since copper ions are toxic to organisms especially phytoplankton, the presence of organic chelators is thought to be important for preventing the occurrence of toxic effects. This research has been focused in three areas. The first involves the measurement of the complexing capacity of local waters, i.e., Biscayne Bay. The second area of research concerns the comparison of various techniques for concentrating the organic fraction from seawater. The third area involves the establishment of the chemical nature of these organic chelators.

The complexing capacity of Biscayne Bay waters varies from $2.4 \times 10^{-2}$ to 0.16 micromoles ( 1.5 to $10 \mathrm{ppb}$ Cu equivalents). The values are highest inshore and at low tide:

Several different techniques have been tested for their ability to concentrate the chelating organics. The strong chelators are completely retained by a "500 molecular weight" ultrafiltration membrane. This technique is, however, extremely slow. Neither chloroform, butanol, XAD-2 nor acetylated polyamide resin extracts the metal-ligand complex at natural seawater pH. A C-18 silica gel bonded phase trap removed only a small portion of the metal complexes at natural $\mathrm{pH}$. This fraction was of molecular weight greater than 5,000. Present results indicate that much but not all of the chelating organics are trapped on XAD-2 resin when the solution $\mathrm{pH}$. is adjusted to 2. Further studies are being carried out involving the use of the other extraction techniques at ph 2.

The third research area is the most significant of the three but is, however, the most challenging experimentally. The question to be answered is: what is the chemical nature of these chelators? Since very little is known concerning the chemical nature of the majority of the organic matter in seawater, one starts out with very little to go on. One thing is certain, however. For an organic ligand 
to be an effective copper chelator in seawater it must chelate so strongly with copper as compared to metals such as calcium and magnesium that the high concentrations of these latter metals do not completely tip the scales in their favor.

A novel method has been established to determine the effective capability of the organics to chelate copper as a function of molecular weight. A sephadex G-25 column equilibrated with seawater which has been spiked with a small amount of copper (5-10 ppb) is utilized. The organic concentrate is applied to the column and the metal content and the UV absorbance of the eluent measured simultaneously. The presence of a chelator is marked by a metal content higher than the baseline concentration: The results from a sample of coastal water indicate that the complexing ligands have a range of molecular weights, and that the distribution of UV absorbance has a maximum which occurs at a higher molecular weight than does the maximum in the distribution of the copper chelators. Thus, the chelating capability of a fraction is not proportional to its UV absorbance.

Further experiments will be performed in order to determine the chemical nature of the organic chelators. These experiments involve the treatment of the. organic extract with reagents that selectively block or destroy certain types of potential chelating sites and the application of this treated sample to the column to look for changes in the chelating capacity.

The combined findings from the studies in the three research areas will result in a more complete view of the chemistry of copper in coastal waters. The results obtained may be specific to this geographic area but the techniques and the methodology involved are of general utility. However, further work will be needed to ex-waters from different water bodies in order to determine how generally applicable the resuits from Biscayne Bay are to the world's oceans.

Symposium on Dissertation on Chemical Oceanography, Oct. 8-12, 1979, Miami, F1a., p. 12. 